\title{
A systematic review of the health-related quality of life and economic burdens of anorexia nervosa, bulimia nervosa, and binge eating disorder
}

\author{
Tamás Ágh $^{1}$ - Gábor Kovács ${ }^{1}$ - Dylan Supina ${ }^{2}$ Manjiri Pawaskar ${ }^{2}$. \\ Barry K. Herman ${ }^{3} \cdot$ Zoltán Vokó $^{1,4} \cdot$ David V. Sheehan ${ }^{5}$
}

Received: 9 December 2015 / Accepted: 17 February 2016/Published online: 4 March 2016

(C) The Author(s) 2016. This article is published with open access at Springerlink.com

\begin{abstract}
Purpose To perform a systematic review of the healthrelated quality of life (HRQoL) and economic burdens of anorexia nervosa (AN), bulimia nervosa $(\mathrm{BN})$, and binge eating disorder (BED).

Methods A systematic literature search of English-language studies was performed in Medline, Embase, PsycINFO, PsycARTICLES, Academic Search Complete, CINAHL Plus, Business Source Premier, and Cochrane Library. Cost data were converted to 2014 Euro.

Results Sixty-nine studies were included. Data on HRQoL were reported in 41 studies (18 for AN, 17 for BN, and 18 for BED), on healthcare utilization in 20 studies (14 for $\mathrm{AN}, 12$ for BN, and 8 for BED), and on healthcare costs in 17 studies (9 for AN, 11 for BN, and only 2 for BED). Patients' HRQoL was significantly worse with AN, BN, and BED compared with healthy populations. AN, BN, and BED were associated with a high rate of hospitalization,
\end{abstract}

Electronic supplementary material The online version of this article (doi:10.1007/s40519-016-0264-x) contains supplementary material, which is available to authorized users.

Tamás Ágh

tamas.agh@syreon.eu

1 Syreon Research Institute, 119 Thököly Street, 1146 Budapest, Hungary

2 Formerly of Shire, 300 Shire Way, Lexington, MA 02421, USA

3 Shire, 300 Shire Way, Lexington, MA 02421, USA

4 Department of Health Policy and Health Economics, Faculty of Social Sciences, Eötvös Loránd University, 1/a Pázmány Péter Street, 1117 Budapest, Hungary

5 University of South Florida College of Medicine, 12901 Bruce B. Downs Boulevard, Tampa, FL 33612, USA outpatient care, and emergency department visits. However, patients rarely received specific treatment for their eating disorder. The annual healthcare costs for $\mathrm{AN}, \mathrm{BN}$, and BED were $€ 2993$ to $€ 55,270$, $€ 888$ to $€ 18,823$, and $€ 1762$ to $€ 2902$, respectively.

Conclusions AN, BN, and BED have a serious impact on patient's HRQoL and are also associated with increased healthcare utilization and healthcare costs. The burden of BED should be examined separately from that of BN. The limited evidence suggests that further research is warranted to better understand the differences in long-term HRQoL and economic burdens of $\mathrm{AN}, \mathrm{BN}$, and BED.

Keywords Eating disorders - Quality of life - Cost of illness $\cdot$ Anorexia nervosa $\cdot$ Bulimia nervosa $\cdot$ Binge eating disorder

\section{Introduction}

Anorexia nervosa (AN), bulimia nervosa (BN), and binge eating disorder (BED) are prevalent psychiatric disorders that are characterized by different symptoms. Based on mixed gender surveys, the lifetime prevalence of $\mathrm{AN}$ is estimated to be approximately $0.5-0.6 \%$, that of BN $0.5-1 \%$, and that of BED 1.1-2.3\% [1-3]. The onset of the majority of eating disorders (EDs) occurs between the ages of 10-20 years; however, in contrast to AN and BN, BED often occurs in older cohorts [3]. AN, BN, and BED are associated with numerous physical (e.g., diabetes, hypertension, ulcers) and mental health conditions (e.g., anxiety disorder, depression) [2, 4-7]. Furthermore, patients with EDs have significantly elevated mortality rates compared with the standard population norms as well as higher suicide rates $[8,9]$. 
Despite the major public health burden of $\mathrm{AN}, \mathrm{BN}$, and $\mathrm{BED}$, there is lack of evidence on the differences in the health-related quality of life (HRQoL) and economic impact of different EDs [10, 11]. The objective of this study is to perform a systematic review of the published literature on the HRQoL and economic burdens of $\mathrm{AN}$, $\mathrm{BN}$, and BED. To our knowledge, no systematic review has been published on this topic to date.

\section{Materials and methods}

This systematic review was based on an extensive literature search on the epidemiology, and HRQoL and economic burdens of EDs (i.e., AN, BN, BED, and eating disorders not otherwise specified [EDNOS]). The literature search was conducted in 2013 using Medline, Embase (via Scopus), PsycINFO, PsycARTICLES, Academic Search Complete, CINAHL Plus, Business Source Premier (via Ebsco Host), and Cochrane Library. The search terms are detailed in Online Resource 1. The search results were processed in two steps: first, the titles and abstracts of all the articles were screened; next, all the potentially relevant articles were analyzed in full text. The references of the included articles were screened for additional eligible studies. The literature screening was conducted by two independent reviewers and disagreements were resolved by the principal researcher.

The reasons for exclusion were as follows for the articles: (1) was not written in English; (2) was not published in a peer-reviewed journal; (3) was an editorial, letter, case report, or review; (4) was not specific to $\mathrm{AN}, \mathrm{BN}$, or BED; and (5) had an objective other than studying the HRQoL and/or economic burden (i.e., healthcare resource utilization, healthcare costs, and societal costs) of $\mathrm{AN}, \mathrm{BN}$, or BED. This review includes only publications in which AN, $\mathrm{BN}$, and BED samples were clearly separated.

The following information was extracted from each included study: (1) the first author and year of publication; (2) the country; (3) the study design; (4) the study year; (5) the included $\mathrm{ED}(\mathrm{s})$; (6) the diagnostic criteria for EDs; (7) the characteristics of the study sample [sample size, \% of female, age, and body mass index (BMI)]; (8) data on the HRQoL burden (HRQoL instrument, main findings); (9) data on healthcare utilization (i.e., resource use data on primary care, outpatient services, and inpatient care including emergency services); and (10) data on healthcare costs (i.e., the costs generated by health service utilization and medication use) and/or societal costs (i.e., costs related to the loss of productivity and symptomrelated food costs) (perspective of the analysis, year of pricing, resource use and/or cost categories, and resource use and/or cost data).
To compare costs across studies, the costs were extrapolated to annual costs per case and inflated to year 2014 values, using country-specific GDP (gross domestic product) deflators. The costs were converted into United States (US) dollars where necessary, using purchasing power parities and then exchanged to euro $(€)$ using the average annual US dollar/euro exchange rate for 2014 (0.7536). If the year of pricing was not referenced, the midpoint in the observation period was assumed to be the base year; if no observation period was reported, the year of publication was adopted as the base year.

\section{Results}

The systematic literature search resulted in 7211 hits. The screening of titles and abstracts identified 540 potentially eligible articles. Finally, 69 studies were included in this review. Two records were identified through a hand search of the references of the relevant articles. A flow diagram of the systematic literature search, based on the Preferred Reporting Items for Systematic Reviews and Meta-Analyses (PRISMA) template [12], is presented in Fig. 1. The characteristics of the reviewed studies are detailed in Online Resource 2.

\section{Health-related quality of life burden}

Data on the HRQoL of $\mathrm{AN}, \mathrm{BN}, \mathrm{BED}$, and relatives/caregivers of ED patients were reported in 41 studies: 18 for AN [13-30], 17 for BN [13-15, 17, 20-25, 27, 2934], 18 for BED [17, 21, 22, 24, 35-48], and 5 for the relatives/caregivers of ED patients [49-53]. Seventeen types of HRQoL instruments were applied in the included studies. The Medical Outcome Study Short Forms (i.e., Short Form 36 [SF-36] and Short Form 12 [SF-12]) were the most commonly used $(n=19)$ HRQoL questionnaires and were administered alone [16, 17, 19, 21, 24-27, 32, 33, $36,38,40,42,43]$ or in combination with other HRQoL questionnaires [13, 22, 23, 37] (Table 1). The reported HRQoL data are summarized in Online Resource 3.

Patients with $\mathrm{AN}, \mathrm{BN}$, and BED were shown to have significantly lower HRQoL than the general population [18, 34, 37, 39, 40, 43]. Many of the included studies investigated the differences between the HRQoL impact of AN, BN, and BED/EDNOS. One of these studies evaluated patients with $\mathrm{AN}$ or $\mathrm{BN}$ and compared them to healthy subjects [20]. Both ED groups showed significantly more impairment than controls in the health domains of the Nottingham Health Profile (NHP), and the AN patients had significantly reduced mobility compared with the $\mathrm{BN}$ patients and the healthy controls. Three studies compared patients with $\mathrm{AN}, \mathrm{BN}$, or BED. One of them showed no 
Fig. 1 The flow diagram of the systematic literature search

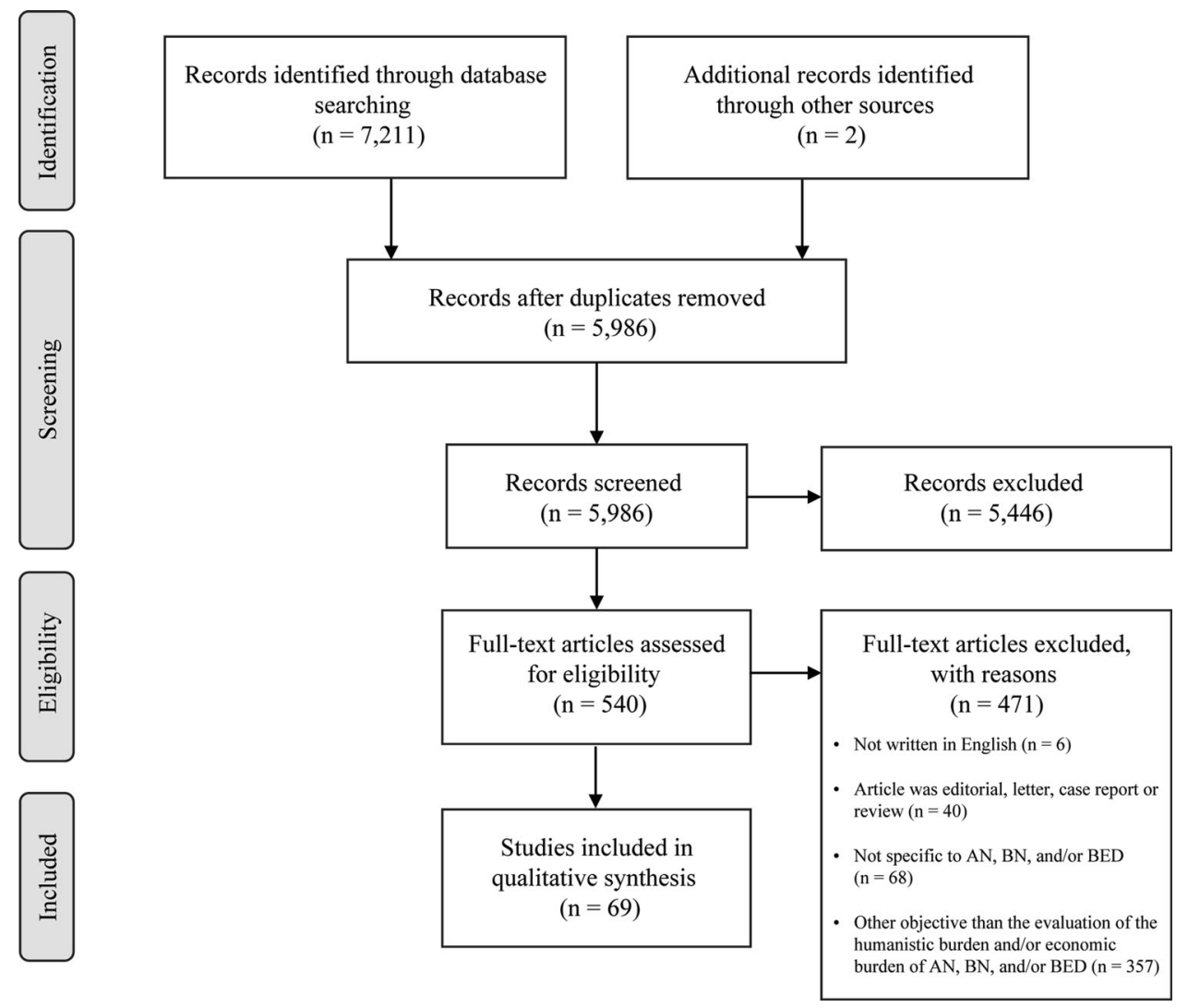

[0.98] vs. 2.58 [1.06] vs. 3.58 [1.01], respectively). Rie et al. [25] could not show any HRQoL difference on comparing $\mathrm{AN}, \mathrm{BN}$, and EDNOS groups to each other, but all of the ED patients had significantly poorer HRQoL than the normal reference group. Focusing on EDNOS [27], no differences were detected between the EDNOS and BN groups on the SF-36 General Health and Healthy Status scales, but AN was associated with lower scores on the Social Functioning, Vitality, and Physical Functioning scales than EDNOS. Bamford et al. [15] found lower Psychological and Physical/Cognitive Scale scores (using the Eating Disorder Quality of Life [EDQoL] instrument) in AN than in BN and EDNOS. Latner et al. [21] found that SF-36 scores were worse in those with subjective bulimic episodes, food avoidance, laxative abuse, and self-induced vomiting, and that PCS scores were worse in those with subjective bulimic episodes and food avoidance. However, these authors did not find differences in HRQoL between $\mathrm{AN}, \mathrm{BN}, \mathrm{BED}$, and EDNOS.

Eight studies investigated the separate and joint effects of BED and obesity (defined as BMI $\geq 30 \mathrm{~kg} / \mathrm{m}^{2}$ ) on HRQoL [36, 37, 40, 41, 43-46]. The results of Masheb et al. [43] showed that BED patients with obesity had significantly lower scores on several SF-36 subscales (i.e., Physical Functioning, Bodily Pain, General Health, Vitality, Social Functioning, and PCS) than those without 


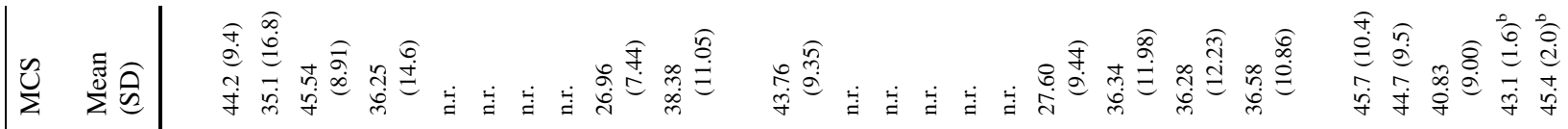

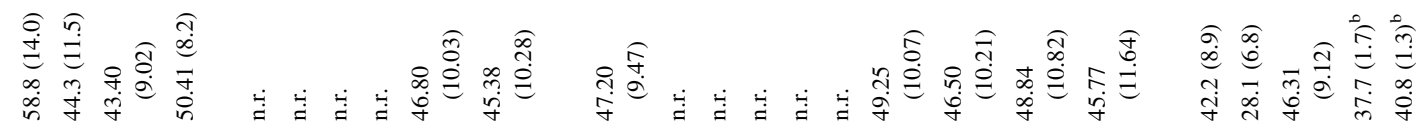

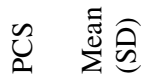

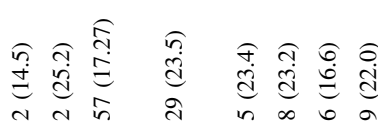

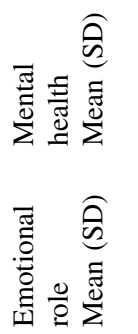
๙ู่

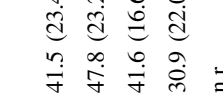

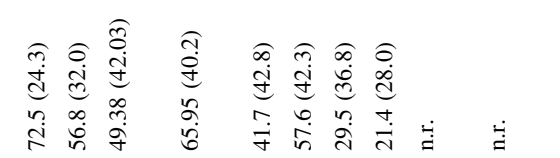

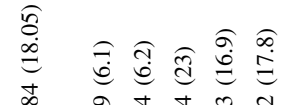

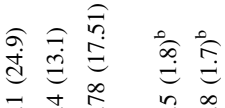

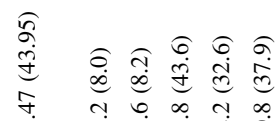

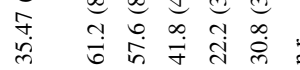

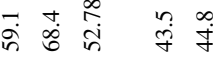

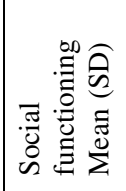

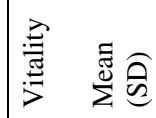

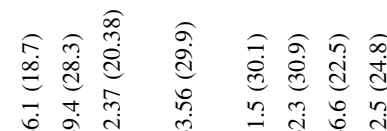

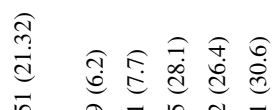

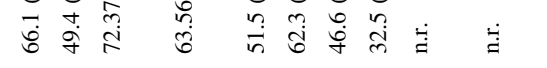

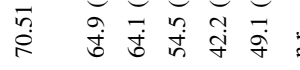

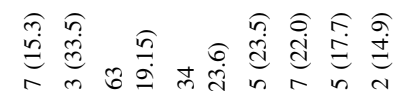

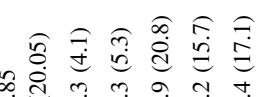

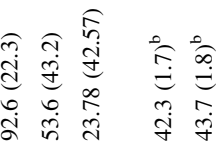

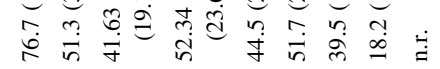

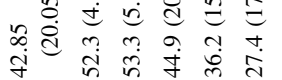
胥

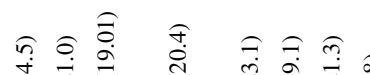

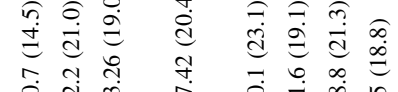

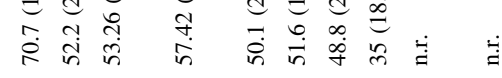

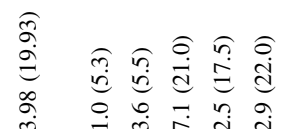

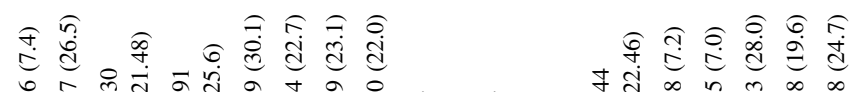

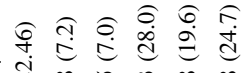

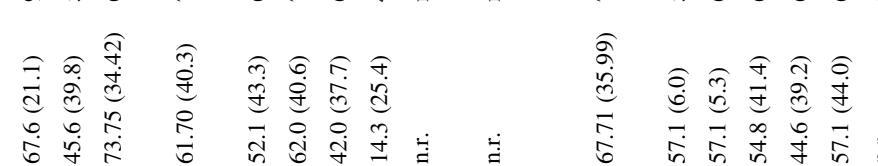

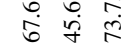
$\dot{\square} \dot{\Xi}$

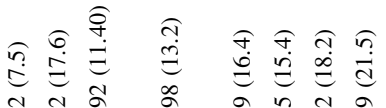

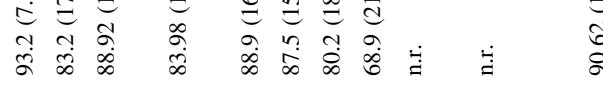

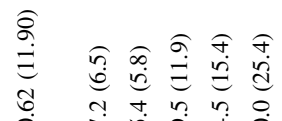

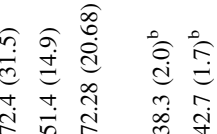




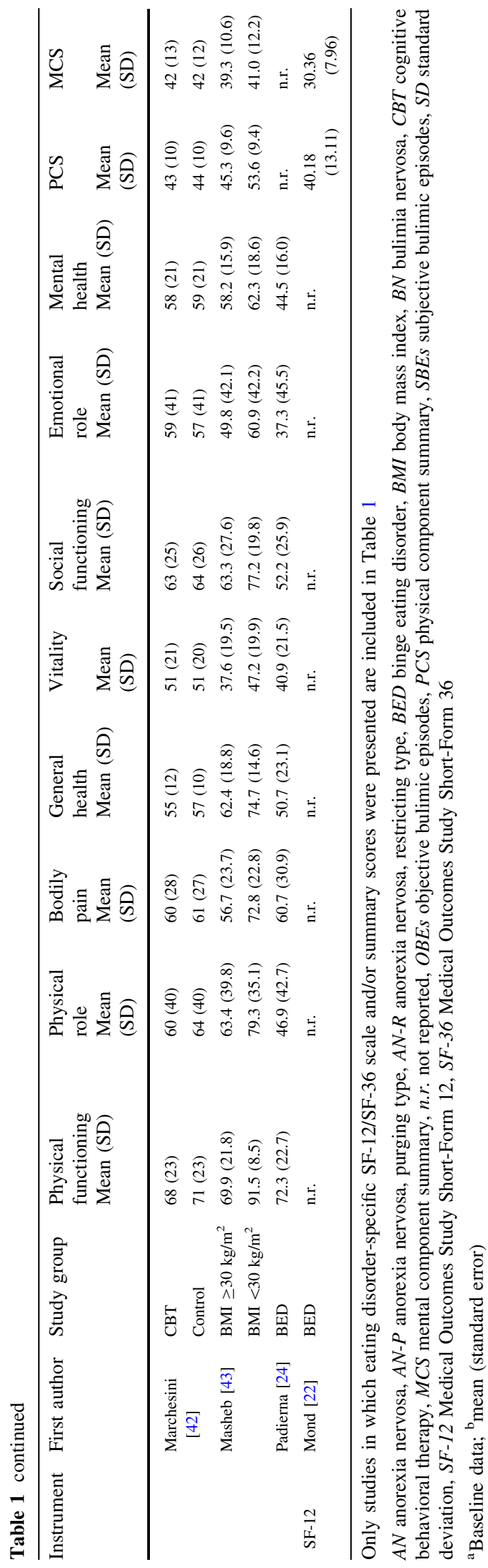

obesity (the PCS mean [SD] scores in patients with BMI $\geq 30 \mathrm{~kg} / \mathrm{m}^{2}$ and BMI $<30 \mathrm{~kg} / \mathrm{m}^{2}$ were: 45.3 [9.6] vs. 53.6 [9.4], respectively, $P=0.001$ ). Among obese individuals, all but two studies [41, 45] concluded that BED patients had significantly reduced HRQoL compared with individuals without BED $[36,37,46]$, even in a population with extreme obesity (defined as BMI $\geq 40 \mathrm{~kg} / \mathrm{m}^{2}$ ) [40] (Online Resource 3). Perez et al. [44] found that obesity was more strongly related to physical HRQoL variables, but BED was more predictive of the mental health and social functioning HRQoL variables. In contrast, Ricca et al. [45] did not find any significant differences in HRQoL between those obese patients without BED, those with threshold, and those with subthreshold BED (defined by a minimum average binge eating [BE] frequency of once a month for a minimum duration of 6 consecutive months). In the study conducted by Kolotkin et al. [41], BED was shown to be associated with more impaired HRQoL in obese individuals (the IWQOL mean (SD) total scores in the BED and non-BED patients were: 51.5 (21.9) vs. 65.3 (19.8), respectively, $P<0.001$ ), but BED did not prove to be an independent factor of weight-related quality of life after controlling for BMI, demographic variables, and psychological variables.

The HRQoL burden of EDs is determined not only by the deficit in HRQoL of the patients themselves, but also by the potential deficit of close relatives who live with the patient or caregivers and take care of an ED patient. A study found that $80 \%$ of the siblings of adolescent ED patients reported that their HRQoL was negatively affected by the onset of their siblings' ED [49]. De La Rie et al. [50] showed that the caregivers of ED patients had worse HRQoL than normal controls (mean SF-36 scale scores: 56.2 [Vitality] to 90.4 [Physical Functioning] vs. 68.6 [Vitality] to 84.0 [Social Functioning], respectively). The caregivers' perceived burden improved significantly over the first year of follow-up, but no further improvement was observed with longer follow-up [51]. Many factors were associated with higher caregiver burden, such as higher anxiety and depression, purgative behaviors, lower patient HRQoL [52], and low-level education [53].

\section{Economic burden}

Twenty studies reported data on healthcare utilization: 14 for AN [3, 54-66], 12 for BN [2, 3, 34, 54, 58-62, 64-67], and 8 for BED [2, 3, 39, 59, 65, 66, 68, 69]. The healthcare utilization data extracted from the included studies are provided in Online Resource 4.

AN (78 \%), BN (88\%), and BED (73\%) were associated with increased health service use (for any treatment, lifetime) compared with individuals without an eating disorder $(44 \%)$ [66]. In the study conducted by Striegel- 
Moore et al. [69], the number of 12-month total health service days (i.e., inpatient care, outpatient care, and emergency care) of BED patients (11.8-21.4) was higher than in the healthy comparison group (3.4-8.4), but it was similar to the utilization found in other major psychiatric disorders (6.9-18.4). The health service use in AN was reported to be equal to or higher than in BN or BED [3, 54, 58-62, 64, 65]. The difference in healthcare utilization between the AN and BN patients was largest in the case of hospitalization. The length of hospital stay was found to be much longer for patients with AN (15.0-52.7 days) than for those with BN (9.0-45.7 days) [54, 58, 60, 61, 64].

Only one study evaluated the effect of obesity (defined as BMI $\geq 30 \mathrm{~kg} / \mathrm{m}^{2}$ ) on health service use in patients with BED. In the study by Striegel-Moore et al. [69], the number of 12-month total health service days (i.e., inpatient care, outpatient care, and emergency care) was found to be higher for obese BED women (mean [SD] total service days: 21.4 [28.1]) than for nonobese BED women (mean [SD] total service days: 11.8 [21.8]); however, the association between obesity and health service use was not significant.

In the assessed studies, patients with $\mathrm{AN}, \mathrm{BN}$, or BED rarely received treatment for their $\mathrm{ED}$, but received more frequent treatment for comorbid psychiatric symptoms and/ or weight loss $[2,3,59,66]$. In the study conducted by Mond et al. [59] on AN, BN, and BED, 22, 14, and $23 \%$ of the patients, respectively, were treated by a mental health professional, specifically for their ED in their lifetime.

Data on healthcare costs were reported in 17 studies: 9 for AN [58, 60, 61, 70-75], 11 for BN [31, 34, 58, 60, 61, 73, 75-79], and 2 for BED [39, 68]. In the reviewed studies, the annual healthcare costs for AN, BN, and BED ranged from $€ 2993$ [61] to $€ 55,270$ [71], $€ 888$ [78] to $€ 18,823$ [79], and $€ 1762$ [39] to $€ 2902$ [68], respectively (Table 2). Detailed information on the reported healthcare costs is presented in Online Resource 5.

The healthcare costs of $\mathrm{AN}, \mathrm{BN}$, and BED were not compared in any of the included studies. However, 5 studies contrasted AN with BN [58, 60, 61, 73, 75] (Online Resource 2). In most of these studies, AN was found to be associated with considerably higher annual healthcare costs than BN (€5952 vs. $€ 1460$ [58], $€ 18,587$ vs. $€ 11,406$ [60], and $€ 5445$ vs. $€ 3386$ [73]). However, Mitchel et al. [75] estimated higher costs for BN (€6279) than AN (€3221). Striegel-Moore et al. [61] assessed the cost of EDs (i.e., $\mathrm{AN}, \mathrm{BN}$, and EDNOS) and compared these costs with the costs of other mental disorders (i.e., obsessive-compulsive disorder and schizophrenia). AN (€6590 for female, €2993 for male) and BN (€3229 for female, €4235 for male) patients had higher costs than obsessive-compulsive disorder patients ( $€ 2104$ for female, $€ 1965$ for male) [61]. The healthcare costs for men with AN and BN were slightly less than the costs for men with schizophrenia (€5552); however, the costs were higher for women with schizophrenia compared to BN (€5259). The healthcare costs for patients with $\mathrm{BN}$ were comparable to the costs associated with the treatment of EDNOS (female €3229, male $€ 4235$ vs. female $€ 3496$, male $€ 2360$ [61], and $€ 6279$ vs. $€ 6514$ [75]). In one of the two studies that examined the costs of BED, the annual healthcare cost of overweight/ obese BED women $(€ 1,762)$ was reported to be $36.5 \%$ higher than that of the age- and sex-matched national average [39]. Grenon et al. [39] found no association with BMI (after controlling for age) and the total healthcare costs in BED. However, this finding is in contrast to the study by Dickerson et al. [68] that showed a significant association with higher BMI and higher mental health medication and total medication costs in women with BED or recurrent $\mathrm{BE}$.

In $\mathrm{AN}$, premature death in the young patient population leads to significant indirect costs to society ( $63 \%$ of the overall costs), mainly due to the loss of production [58]. Symptom-related costs for food are considerable expense factors for patients with BN. Crow et al. [76] found that costs associated with $\mathrm{BE}$ and purging in $\mathrm{BN}$ accounted for $32.7 \%$ of the total food costs; the mean total annual food cost per BN patient was $€ 4735$. No study was identified for BED-related food costs.

\section{Discussion}

A comprehensive review on the differences in the HRQoL and economic impact of $\mathrm{AN}, \mathrm{BN}$, and BED was missing from the literature. We analyzed 69 studies: data on HRQoL were reported in 41 studies ( 18 for AN, 17 for BN, and 18 for BED), on healthcare utilization in 20 studies (14 for $\mathrm{AN}, 12$ for $\mathrm{BN}$, and 8 for BED), and on healthcare costs in 17 studies ( 9 for $\mathrm{AN}, 11$ for BN, and 2 for BED).

Generally, AN, BN, or BED was associated with significantly impaired HRQoL compared with the healthy population [18, 34, 37, 39, 40, 43]. Evidence also suggests that patients with EDs have impaired HRQoL compared to those with other psychiatric conditions [80]. Studies showed that obesity was associated with further deterioration of HRQoL of patients with BED [36, 37, 40, $43,46]$. In addition, other psychopathology factors (e.g., depression and anxiety) were associated with lower HRQoL of patients with AN, BN, and BED [19, 21, 24, 39, 43]. AN, BN, and BED may have differential effects on HRQoL compared with each other, depending mainly, but not exclusively, on the study design and the HRQoL domains investigated $[15,17,22,27]$. The reviewed studies provided a range of results, at least partially due to the heterogeneity in the patient population and the 
Table 2 Annual cost per patient data on AN, BN, and BED

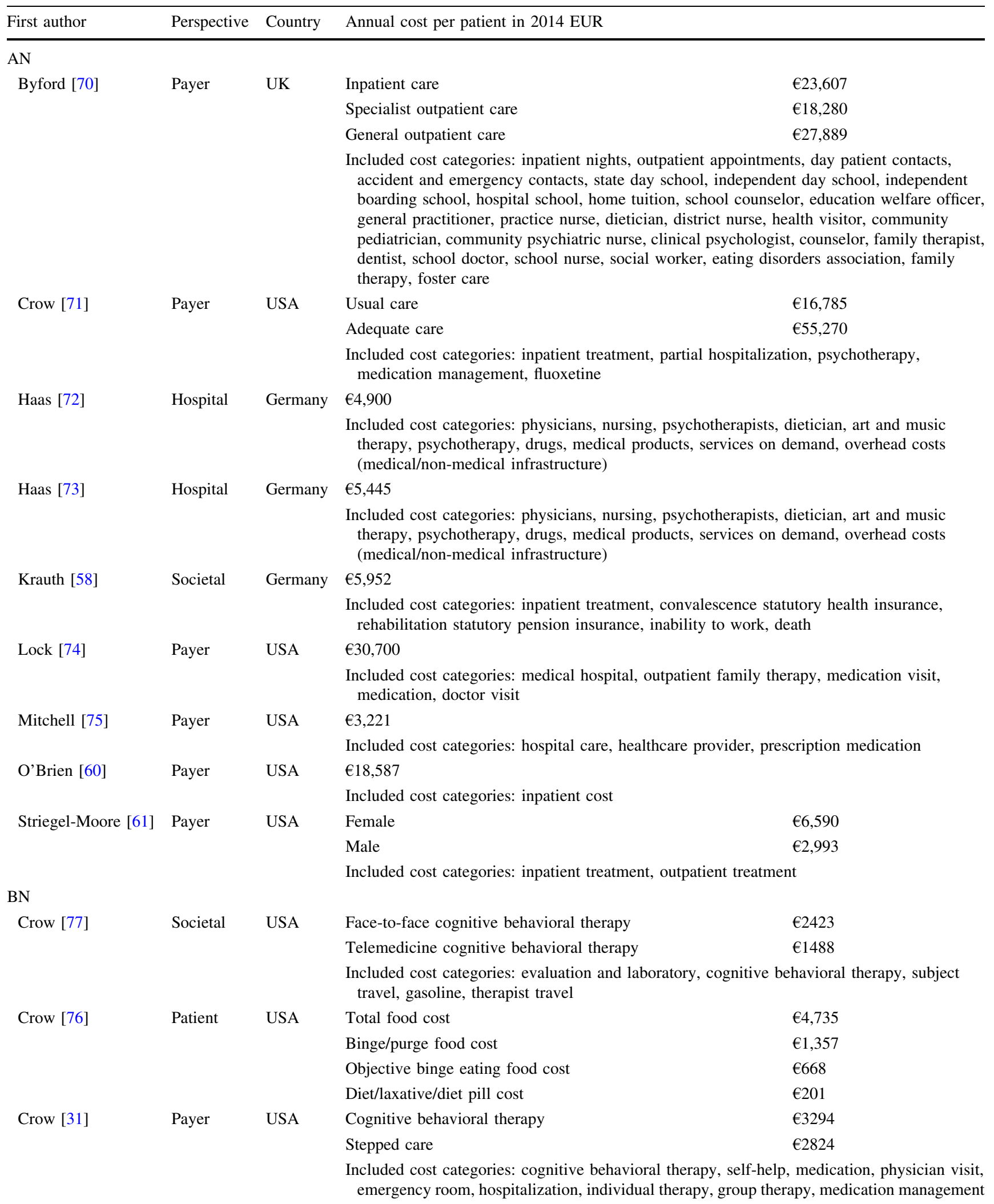


Table 2 continued

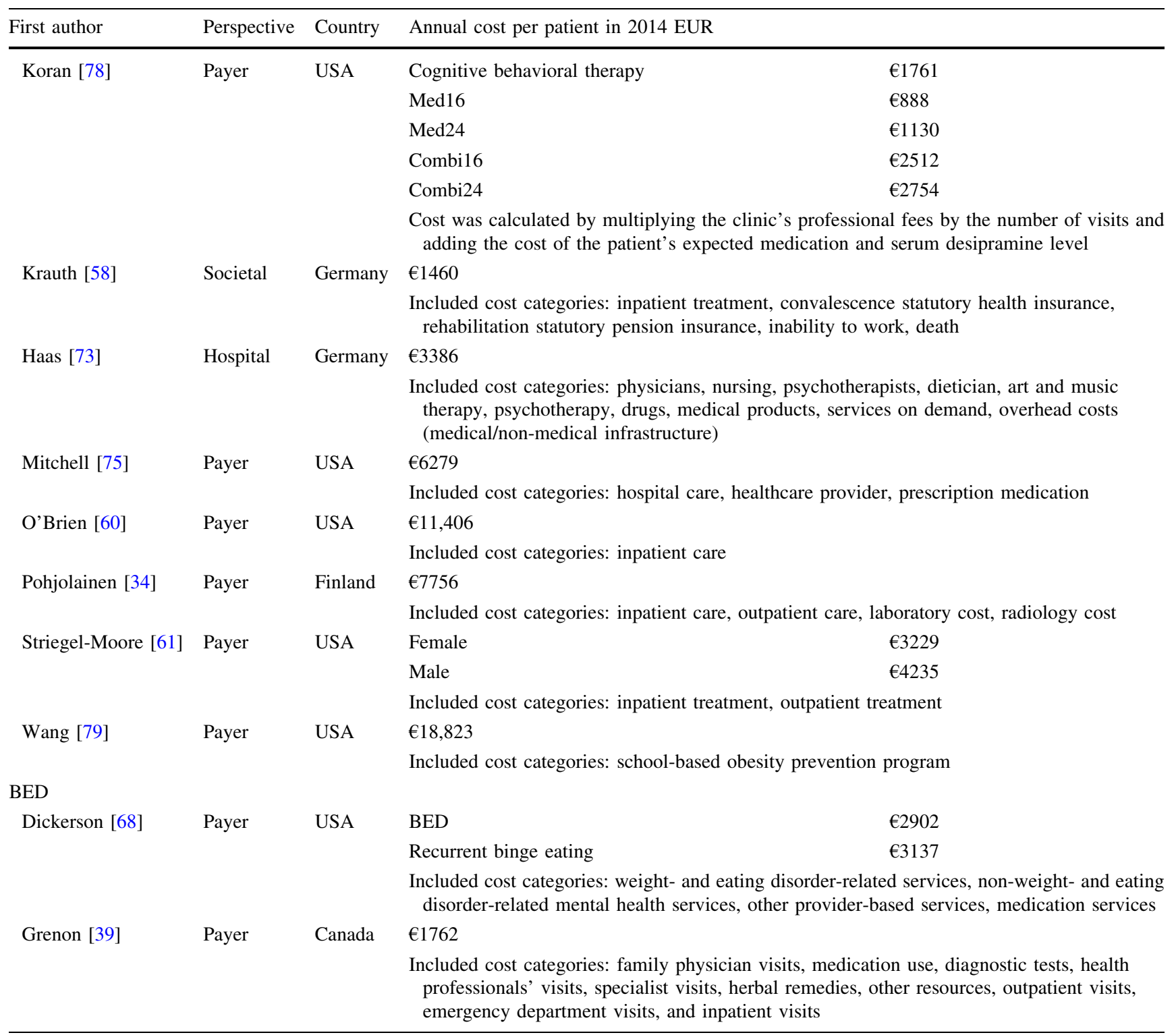

$A N$ anorexia nervosa, $B E D$ binge eating disorder, $B N$ bulimia nervosa, EUR euro

research design. Consequently, the study results and conclusions seemed to be quite heterogeneous. It is difficult to draw a consistent conclusion on the relative effects of the assessed EDs on HRQoL, which may be because $\mathrm{AN}, \mathrm{BN}$, and BED share certain psychopathology symptoms (e.g., loss of control of eating appears both in $\mathrm{BN}$ and BED). In a recently published meta-analysis, Winkler et al. [81] could also not identify any specific differences between the HRQoL effects of different ED diagnostic groups. The HRQoL of the siblings and caregivers of $\mathrm{AN}, \mathrm{BN}$, and BED patients was also found to be impaired [49-53].
The economic impacts of EDs has been receiving increasing research attention in recent years [82-84]; however, a comparative review on the economic burden of $\mathrm{AN}, \mathrm{BN}$, and BED was lacking in the literature. Based on the reviewed studies, AN, BN, and BED are associated with increased healthcare utilization and higher healthcare costs. The evaluated EDs are associated with a high rate of hospitalization, outpatient care, and emergency department visits $[3,54,58-62,64-66,69]$. However, inpatient care seems to be more common in AN [54, 58, 60, 61, 64], which could primarily be due the severity of the condition. It was also notable that patients rarely receive specific 
treatment for their ED and mostly received treatment for general mental health, comorbid psychiatric symptoms, and/or weight loss $[2,3,59,66]$. Improvement in diagnosis, reporting/coding and management of $\mathrm{AN}, \mathrm{BN}$, and $\mathrm{BED}$ may improve treatment for these patients.

The cost estimates varied considerably for $\mathrm{AN}, \mathrm{BN}$, and $\mathrm{BED}$, as well as within particular disorders. Several differences in the design and analysis of the cost of illness in the studies reduced the comparability of the cost data. The annual direct healthcare costs of $\mathrm{AN}$ and $\mathrm{BN}$ appeared to be similar to those of other major psychiatric conditions [61]. Compared with BN, AN was associated with higher healthcare costs in most assessed studies [58, 60, 72]. Healthcare cost data showed variation across countries; however, an investigation of the factors behind the crosscountry differences was beyond the scope of this review (differences in treatment patterns and evaluated cost factors as well as national characteristics of the healthcare systems are likely to be key determinants).

Compared to BN, obesity appears to be more common in BED [2]. Due to the limited number of studies, it is not possible to definitively separate burden specific to BED from those associated with obesity. Namely, a higher level of BMI decreases the physical HRQoL of individuals (e.g., worst physical functioning) [85]. Nevertheless, BED is distinct from obesity; there is a unique psychopathology and medical risk profile associated with BED [86]. Patients with BED have greater functional impairment, lower HRQoL, and more subjective distress compared to weight-matched obese individuals without BED $[36,37,40,44,46]$. This suggests that at least part of the burden of BED is unique to the disorder and provides a rationale for not only treating weight issues, but the disorder itself to fully address the burden of BED. However, obesity may have severe health consequences over time (e.g., diabetes and hypertension), which may have an impact on the long-term burden of BED. Although BED is the most prevalent ED, there is scarcity of information on the economic burden of BED; those studies that do report the economic burden of BED, most reported it in combination with $\mathrm{BN}$ or overall EDs (only 2 studies reported healthcare cost data for BED [39, 68]). Further research is needed on this topic, because data on the long-term health and economic impact of BED are essential to better establish the burden of illness in this patient population.

Our findings should be considered in light of the following limitations. The current systematic literature review involved searching only studies that were published in English and indexed in the selected databases. Despite the broad database selection, the inclusion of unpublished material and studies from other resources was precluded. As a further effort, we screened the references of the included articles for additional eligible studies. No formal quality assessment of the identified publications was performed, because of the large heterogeneity in the study types of the included studies.

In summary, AN, BN, and BED markedly impair HRQoL and are associated with increased healthcare use and costs compared with healthy individuals. The HRQoL impairment of $\mathrm{AN}, \mathrm{BN}$, and BED patients was found to be similar; however, healthcare utilization (especially, inpatient care) and costs were reported to be higher for $\mathrm{AN}$ patients than for $\mathrm{BN}$ and $\mathrm{BED}$ patients. Compared to $\mathrm{BN}$, obesity appears to be more common in patients with BED, which may contribute to significant impairment of their HRQoL and higher healthcare use, especially in the long term. Thus, the burden of BED should be examined separately from that of $\mathrm{BN}$. The limited evidence indicates that further research is warranted to better understand the differences between the HRQoL and economic burdens of $\mathrm{BED}$ in contrast to $\mathrm{AN}$ and $\mathrm{BN}$ in the long term.

Acknowledgments Editorial assistance in the form of proofreading, copyediting, and formatting was provided by Complete Healthcare Communications, LLC (CHC, Chadds Ford, PA, USA). Under the direction of the authors, editing assistance was provided by Stefan Kolata, Ph.D, and Craig Slawecki, PhD, employees of CHC.

\section{Compliance with ethical standards}

Funding This research was financially supported by Shire Development LLC (Lexington, MA, USA).

Conflicts of interest Tamás Ágh, Gábor Kovács, and Zoltán Vokó are employees of the Syreon Research Institute. Dylan Supina was an employee of Shire at the time this research was conducted and holds stock and/or stock options in Shire. Manjiri Pawaskar was an employee of Shire at the time this research was conducted and is now an employee of Merck; she holds stock and/or stock options in Shire and Merck. Barry K. Herman is an employee of Shire and holds stock and/or stock options in Shire Development LLC. David V. Sheehan has served as a consultant to Shire and is the creator of a scale that measures functional impairment (Sheehan Disability Scale).

Ethical approval This article does not contain any studies with human participants or animals performed by any of the author.

Informed consent For this type of study, formal consent is not required.

Open Access This article is distributed under the terms of the Creative Commons Attribution 4.0 International License (http://crea tivecommons.org/licenses/by/4.0/), which permits unrestricted use, distribution, and reproduction in any medium, provided you give appropriate credit to the original author(s) and the source, provide a link to the Creative Commons license, and indicate if changes were made.

\section{References}

1. Hudson JI, Hiripi E, Pope HG Jr, Kessler RC (2007) The prevalence and correlates of eating disorders in the National 
Comorbidity Survey Replication. Biol Psychiatry 61:348-358. doi:10.1016/j.biopsych.2006.03.040

2. Kessler RC, Berglund PA, Chiu WT et al (2013) The prevalence and correlates of binge eating disorder in the World Health Organization World Mental Health Surveys. Biol Psychiatry 7:904-914. doi:10.1016/j.biopsych.2012.11.020

3. Preti A, Girolamo G, Vilagut G et al (2009) The epidemiology of eating disorders in six European countries: results of the ESEMeD-WMH project. J Psychiatr Res 43:1125-1132. doi:10. 1016/j.jpsychires.2009.04.003

4. Le Grange D, Swanson SA, Crow SJ, Merikangas KR (2012) Eating disorder not otherwise specified presentation in the US population. Int J Eat Disord 45:711-718. doi:10.1002/eat.22006

5. McBride O, McManus S, Thompson J et al (2013) Profiling disordered eating patterns and body mass index (BMI) in the English general population. Soc Psychiatry Psychiatr Epidemiol 48:783-793. doi:10.1007/s00127-012-0613-7

6. McElroy SL, Frye MA, Hellemann G et al (2011) Prevalence and correlates of eating disorders in 875 patients with bipolar disorder. J Affect Disord 128:191-198. doi:10.1016/j.jad.2010.06.037

7. Agras WS (2001) The consequences and costs of the eating disorders. Psychiatr Clin North Am 24:371-379

8. Button EJ, Chadalavada B, Palmer RL (2010) Mortality and predictors of death in a cohort of patients presenting to an eating disorders service. Int J Eat Disord 43:387-392. doi:10.1002/eat. 20715

9. Rosling AM, Sparén P, Norring C, Von Knorring AL (2011) Mortality of eating disorders: a follow-up study of treatment in a specialist unit 1974-2000. Int J Eat Disord 44:304-310. doi:10. 1002/eat.20827

10. Stuhldreher N, Konnopka A, Wild B et al (2012) Cost-of-illness studies and cost-effectiveness analyses in eating disorders: a systematic review. Int J Eat Disord 45:476-491. doi:10.1002/eat. 20977

11. Hay P, Mond J (2005) How to 'count the cost' and measure burden? A review of health-related quality of life in people with eating disorders. J Mental Health 14:539-552. doi:10.1080/ 09638230500400274

12. Moher D, Liberati A, Tetzlaff J, Altman DG (2009) Preferred reporting items for systematic reviews and meta-analyses: the PRISMA statement. Ann Intern Med 151(264-269):w64. doi:10. 1371/journal.pmed.1000097

13. Abraham S, Kellow J (2011) Exploring eating disorder quality of life and functional gastrointestinal disorders among eating disorder patients. J Psychosom Res 70:372-377. doi:10.1016/j.jpsy chores.2010.11.009

14. Abraham SF, Brown T, Boyd C et al (2006) Quality of life: eating disorders. Aust N Z J Psychiatry 40:150-155

15. Bamford B, Sly R (2010) Exploring quality of life in the eating disorders. Eur Eat Disord Rev 18:147-153. doi:10.1002/erv.975

16. del Valle MF, Pérez M, Santana-Sosa E et al (2010) Does resistance training improve the functional capacity and well being of very young anorexic patients? A randomized controlled trial. J Adolesc Health 46:352-358. doi:10.1016/j.jadohealth.2009.09. 001

17. Doll HA, Petersen SE, Stewart-Brown SL (2005) Eating disorders and emotional and physical well-being: associations between student self-reports of eating disorders and quality of life as measured by the SF-36. Qual Life Res 14:705-717. doi:10.1007/ s11136-004-0792-0

18. Fox AP, Leung N (2009) Existential well-being in younger and older people with anorexia nervosa-a preliminary investigation. Eur Eat Disord Rev 17:24-30. doi:10.1002/erv.895

19. González-Pinto A, Inmaculada F, Cristina R et al (2004) Purging behaviors and comorbidity as predictive factors of quality of life in anorexia nervosa. Int J Eat Disord 36:445-450. doi:10.1002/ eat. 20058

20. Keilen M, Treasure T, Schmidt U, Treasure J (1994) Quality of life measurement in eating disorders, angina, and transplant candidates: are they comparable? J R Soc Med 87:441-444

21. Latner JD, Vallance JK, Buckett G (2008) Health-related quality of life in women with eating disorders: association with subjective and objective binge eating. J Clin Psychol Med Settings 15:148-153. doi:10.1007/s10880-008-9111-1

22. Mond JM, Hay PJ, Rodgers B et al (2005) Assessing quality of life in eating disorder patients. Qual Life Res 14:171-178

23. Muñoz P, Quintana JM, Hayas CL et al (2009) Assessment of the impact of eating disorders on quality of life using the diseasespecific, Health-Related Quality of Life for Eating Disorders (HeRQoLED) questionnaire. Qual Life Res 18:1137-1146. doi:10.1007/s11136-009-9542-7

24. Padierna A, Quintana JM, Arostegui I et al (2000) The healthrelated quality of life in eating disorders. Qual Life Res 9:667-674

25. de la Rie SM, Noordenbos G, van Furth EF (2005) Quality of life and eating disorders. Qual Life Res 14:1511-1522

26. Thien V, Thomas A, Markin D, Birmingham CL (2000) Pilot study of a graded exercise program for the treatment of anorexia nervosa. Int J Eat Disord 28:101-106. doi:10.1002/(SICI)1098108X(200007)28:1<101:AID-EAT12>3.0.CO;2-V

27. Turner H, Bryant-Waugh R, Peveler R (2010) The clinical features of EDNOS: relationship to mood, health status and general functioning. Eat Behav 11:127-130. doi:10.1016/j.eatbeh.2009. 10.006

28. Walsh BT, Kaplan AS, Attia E et al (2006) Fluoxetine after weight restoration in anorexia nervosa: a randomized controlled trial [corrected] [published erratum appears in JAMA 2006 Aug 23;296(8):934]. JAMA 295:2605-2612. doi:10.1001/jama.295. 22.2605

29. Watson HJ, Allen K, Fursland A et al (2012) Does enhanced cognitive behaviour therapy for eating disorders improve quality of life? Eur Eat Disord Rev 20:393-399. doi:10.1002/ erv. 2186

30. Watson HJ, Fursland A, Bulik CM, Nathan P (2013) Subjective binge eating with compensatory behaviors: a variant presentation of bulimia nervosa. Int J Eat Disord 46:119-126. doi:10.1002/eat. 22052

31. Crow SJ, Agras WS, Halmi KA et al (2013) A cost effectiveness analysis of stepped care treatment for bulimia nervosa. Int J Eat Disord 46:302-307. doi:10.1002/eat.22087

32. Mond JM, Latner JD, Hay PH et al (2010) Objective and subjective bulimic episodes in the classification of bulimic-type eating disorders: another nail in the coffin of a problematic distinction. Behav Res Ther 48:661-669. doi:10.1016/j.brat.2010. 03.020

33. Nickel C, Tritt K, Muehlbacher M et al (2005) Topiramate treatment in bulimia nervosa patients: a randomized, doubleblind, placebo-controlled trial. Int J Eat Disord 38:295-300. doi:10.1002/eat.20202

34. Pohjolainen V, Rasanen P, Roine RP et al (2010) Cost-utility of treatment of bulimia nervosa. Int J Eat Disord 43:596-602. doi:10.1002/eat.20754

35. Cassin SE, von Ranson KM, Heng K et al (2008) Adapted motivational interviewing for women with binge eating disorder: a randomized controlled trial. Psychol Addict Behav 22:417-425. doi:10.1037/0893-164X.22.3.417

36. de Zwaan M, Lancaster KL, Mitchell JE et al (2002) Healthrelated quality of life in morbidly obese patients: effect of gastric bypass surgery. Obes Surg 12:773-780. doi:10.1381/ 096089202320995547 
37. de Zwaan M, Mitchell JE, Howell LM et al (2002) Two measures of health-related quality of life in morbid obesity. Obes Res 10:1143-1151

38. Faulconbridge LF, Wadden TA, Thomas JG et al (2013) Changes in depression and quality of life in obese individuals with binge eating disorder: bariatric surgery versus lifestyle modification. Surg Obes Relat Dis 9:790-796. doi:10.1016/j.soard.2012.10.010

39. Grenon R, Tasca GA, Cwinn E et al (2010) Depressive symptoms are associated with medication use and lower health-related quality of life in overweight women with binge eating disorder. Womens Health Issues 20:435-440. doi:10.1016/j.whi.2010.07. 004

40. Hsu LK, Mulliken B, McDonagh B et al (2002) Binge eating disorder in extreme obesity. Int J Obes Relat Metab Disord 26:1398-1403. doi:10.1038/sj.ijo.0802081

41. Kolotkin RL, Westman EC, Ostbye T et al (2004) Does binge eating disorder impact weight-related quality of life? Obes Res 12:999-1005

42. Marchesini G, Natale S, Chierici S et al (2002) Effects of cognitive-behavioural therapy on health-related quality of life in obese subjects with and without binge eating disorder. Int J Obes Relat Metab Disord 26:1261-1267. doi:10.1038/sj.ijo.0802073

43. Masheb RM, Grilo CM (2004) Quality of life in patients with binge eating disorder. Eat Weight Disord 9:194-199

44. Perez M, Warren CS (2012) The relationship between quality of life, binge-eating disorder, and obesity status in an ethnically diverse sample. Obesity (Silver Spring) 20:879-885. doi:10.1038/ oby. 2011.89

45. Ricca V, Castellini G, Sauro C et al (2009) Correlations between binge eating and emotional eating in a sample of owerweight subjects. Appetite 53:418-421. doi:10.1016/j.appet.2009.07.008

46. Rieger E, Wilfley DE, Stein RI et al (2005) A comparison of quality of life in obese individuals with and without binge eating disorder. Int J Eat Disord 37:234-240. doi:10.1002/eat.20101

47. Silveira RO, Zanatto V, Appolinário JC, Kapczinski F (2005) An open trial of reboxetine in obese patients with binge eating disorder. Eat Weight Disord 10:e93-e96

48. Wilfley DE, Crow SJ, Hudson JI et al (2008) Efficacy of sibutramine for the treatment of binge eating disorder: a randomized multicenter placebo-controlled double-blind study. Am J Psychiatry 165:51-58. doi:10.1176/appi.ajp.2007.06121970

49. Areemit RS, Katzman DK, Pinhas L, Kaufman ME (2010) The experience of siblings of adolescents with eating disorders. J Adolesc Health 46:569-576. doi:10.1016/j.jadohealth.2009.12. 011

50. de la Rie SM, van Furth EF, De Koning A et al (2005) The quality of life of family caregivers of eating disorder patients. Eat Disord 13:345-351. doi:10.1080/10640260591005236

51. González N, Bilbao A, Padierna A et al (2012) Validity and reliability of the Spanish version of the Involvement Evaluation Questionnaire among caregivers of patients with eating disorders. Psychiatry Res 200:896-903. doi:10.1016/j.psychres.2012.07.033

52. Martín J, Padierna A, Aguirre U et al (2011) Quality of life among caregivers of patients with eating disorders. Qual Life Res 20:1359-1369. doi:10.1007/s11136-011-9873-z

53. Padierna A, Martín J, Aguirre U et al (2013) Burden of caregiving amongst family caregivers of patients with eating disorders. Soc Psychiatry Psychiatr Epidemiol 48:151-161. doi:10.1007/ s00127-012-0525-6

54. Calderon R, Vander Stoep A, Collett B et al (2007) Inpatients with eating disorders: demographic, diagnostic and service characteristics from a nationwide pediatric sample. Int $\mathrm{J}$ Eat Disord 40:622-628. doi:10.1002/eat.20411

55. George DT, Weiss SR, Gwirtsman HE, Blazer D (1987) Hospital treatment of anorexia nervosa: a 25 year retrospective study from
1958 to 1982. Int J Eat Disord 6:321-330. doi:10.1002/1098108X(198703)6:2<321:AID-EAT2260060216>3.0.CO;2-I

56. Grigoriadis S, Kaplan A, Carter J, Woodside B (2001) What treatments patients seek after inpatient care: a follow-up of 24 patients with anorexia nervosa. Eat Weight Disord 6:115-1120

57. Kalisvaart JL, Hergenroeder AC (2007) Hospitalization of patients with eating disorders on adolescent medical units is threatened by current reimbursement system. Int J Adolesc Med Health 19:155-165

58. Krauth C, Buser K, Vogel H (2002) How high are the costs of eating disorders-anorexia nervosa and bulimia nervosa-for German society? Eur J Health Econ 3:244-250. doi:10.1007/ s10198-002-0137-2

59. Mond JM, Hay PJ, Rodgers B, Owen C (2007) Health service utilization for eating disorders: findings from a community-based study. Int J Eat Disord 40:399-408. doi:10.1002/eat.20382

60. O'Brien JA, Ward A (2003) Cost of providing acute hospitalization for patients with anorexia nervosa and bulimia. Drug Benefit Trends 15:37-42

61. Striegel-Moore RH, Leslie D, Petrill SA et al (2000) One-year use and cost of inpatient and outpatient services among female and male patients with an eating disorder: evidence from a national database of health insurance claims. Int J Eat Disord 27:381-389. doi:10.1002/(SICI)1098-108X(200005)27:4<381: AID-EAT2>3.0.CO;2-U

62. Striegel-Moore RH, DeBar L, Wilson GT et al (2008) Health services use in eating disorders. Psychol Med 38:1465-1474. doi:10.1017/S0033291707001833

63. Wales J, Brewin N, Palmer RL (2013) Anorexia nervosa and low weight EDNOS: a 10-year study of service consumption and outcome in a local specialised service for adults. Eur Eat Disord Rev 21:252-256. doi:10.1002/erv.2202

64. Williamson DA, Thaw JM (2001) Cost-effectiveness analysis of a hospital-based cognitive-behavioral treatment program for eating disorders. Behav Ther 32:459-477. doi:10.1016/S00057894(01)80031-9

65. Marques L, Alegria M, Becker AE et al (2011) Comparative prevalence, correlates of impairment, and service utilization for eating disorders across US ethnic groups: Implications for reducing ethnic disparities in health care access for eating disorders. Int J Eat Disord 44:412-420. doi:10.1002/eat.20787

66. Swanson SA, Crow SJ, Le Grange D et al (2011) Prevalence and correlates of eating disorders in adolescents: results from the national comorbidity survey replication adolescent supplement. Arch Gen Psychiatry 68:714-723. doi:10.1001/arch genpsychiatry.2011.22

67. Jager B, Liedtke R, Lamprecht F, Freyberger H (2004) Social and health adjustment of bulimic women 7-9 years following therapy. Acta Psychiatr Scand 110:138-145. doi:10.1111/j.16000047.2004.00334.x

68. Dickerson J, Debar L, Perrin N et al (2011) Health-service use in women with binge eating disorders. Int J Eat Disord 44:524-530. doi:10.1002/eat.20842

69. Striegel-Moore RH, Dohm FA, Wilfley DE et al (2004) Toward an understanding of health services use in women with binge eating disorder. Obes Res 12:799-806

70. Byford S, Barrett B, Roberts C et al (2007) Economic evaluation of a randomised controlled trial for anorexia nervosa in adolescents. Br J Psychiatry 191:436-440. doi:10.1192/bjp.bp.107.036806

71. Crow SJ, Nyman JA (2004) The cost-effectiveness of anorexia nervosa treatment. Int J Eat Disord 35:155-160. doi:10.1002/eat. 10258

72. Haas L, Stargardt T, Schreyoegg J et al (2012) Inpatient costs and predictors of costs in the psychosomatic treatment of anorexia nervosa. Int J Eat Disord 45:214-221. doi:10.1002/eat.20903 
73. Haas L, Stargardt T, Schreyoegg J et al (2012) Introduction of DRG-based reimbursement in inpatient psychosomatics-an examination of cost homogeneity and cost predictors in the treatment of patients with eating disorders. J Psychosom Res 73:383-390. doi:10.1016/j.jpsychores.2012.09.001

74. Lock J, Couturier J, Agras WS (2008) Costs of remission and recovery using family therapy for adolescent anorexia nervosa: a descriptive report. Eat Disord 16:322-330. doi:10.1080/ 10640260802115969

75. Mitchell JE, Myers T, Crosby R et al (2009) Health care utilization in patients with eating disorders. Int $\mathrm{J}$ Eat Disord 42:571-574. doi:10.1002/eat.20651

76. Crow SJ, Frisch MJ, Peterson CB et al (2009) Monetary costs associated with bulimia. Int J Eat Disord 42:81-83. doi:10.1002/ eat.20581

77. Crow SJ, Mitchell JE, Crosby RD et al (2009) The cost effectiveness of cognitive behavioral therapy for bulimia nervosa delivered via telemedicine versus face-to-face. Behav Res Ther 47:451-453. doi:10.1016/j.brat.2009.02.006

78. Koran LM, Agras WS, Rossiter EM et al (1995) Comparing the cost effectiveness of psychiatric treatments: bulimia nervosa. Psychiatry Res 58:13-21. doi:10.1016/0165-1781(95)02681-L

79. Wang LY, Nichols LP, Austin SB (2011) The economic effect of Planet Health on preventing bulimia nervosa. Arch Pediatr Adolesc Med 165:756-762. doi:10.1001/archpediatrics.2011.105
80. Jenkins PE, Hoste RR, Meyer C et al (2011) Eating disorders and quality of life: a review of the literature. Clin Psychol Rev 31:113-121. doi:10.1016/j.cpr.2010.08.003

81. Winkler LA, Christiansen E, Lichtenstein M et al (2014) Quality of life in eating disorders: a meta-analysis. Psychiatry Res 219:1-9. doi:10.1016/j.psychres.2014.05.002

82. Crow S (2014) The economics of eating disorder treatment. Curr Psychiatry Rep 16:454. doi:10.1007/s11920-014-0454-z

83. Stuhldreher N, Wild B, König HH et al (2015) Determinants of direct and indirect costs in anorexia nervosa. Int $\mathrm{J}$ Eat Disord 48:139-146. doi:10.1002/eat.22274

84. Agh T, Kovacs G, Pawaskar M et al (2015) Epidemiology, health-related quality of life and economic burden of binge eating disorder: a systematic literature review. Eat Weight Disord 20:1-12. doi:10.1007/s40519-014-0173-9

85. Pokrajac-Bulian A, Kukić M, Bašić-Marković N (2015) Quality of life as a mediator in the association between body mass index and negative emotionality in overweight and obese non-clinical sample. Eat Weight Disord 20:473-481. doi:10.1007/s40519015-0208-x

86. American Psychiatric Association (2013) Diagnostic and statistical manual of mental disorders, 5th edn. American Psychiatric Press, Washington 